\title{
An unusual variant of atrophic dermatofibrosarcoma protuberans*
}

\author{
Simone Silva da Costa Aragão ${ }^{1}$ \\ Alberto Eduardo Cox Cardoso ${ }^{1}$
}

\author{
Everson José dos Santos Leite ${ }^{1}$ \\ Ricardo Luiz Simões Houly²
}

DOI: http:/ / dx.doi.org/10.1590/abd1806-4841.20187049

\begin{abstract}
Dermatofibrosarcoma protuberans is an uncommon neoplasm that is most often seen in young adults. The most common clinical presentation is the protruding form; however, other subtypes are known, such as the atrophic. In 2012 there were only 33 reports of this variant in the literature. Many cases of Dermatofibrosarcoma protuberans in children are only discovered in adulthood because they were not diagnosed early. Due the high morbidity, we raise the need for attention from the dermatologist to recognize uncommon neoplasms in the clinical practice. We report a case of a 15-year-old patient diagnosed with atrophic Dermatofibrosarcoma protuberans on the back.
\end{abstract}

Keywords: Dermatofibrosarcoma; Sarcoma; Skin neoplasms; Soft tissue neoplasms

\section{INTRODUCTION}

Dermatofibrosarcoma protuberans (DFSP) is a rare spindle cell mesenchymal malignancy that arises in the dermis, extends to the deep subcutaneous tissue, and can also affect muscles and bones. ${ }^{1}$ Etiology is unknown. It represents $0.1 \%$ of all malignant skin conditions, with no gender predilection and a predominance between the second and fifth decades of life. ${ }^{2}$ It is more commonly localized on the trunk and proximal aspects of the extremities. Its most common clinical presentation is a pink nodule or brownish plaque, surrounded by multiple satellite nodules. However, other subtypes are also known: atrophic, fibrosarcomatous, granular, myxoid, pigmented (Bednar tumor), and sclerosing. ${ }^{3}$

Microscopically, the tumor consists of atypical spindle cells in a fibrotic stroma in the dermis, resulting in a storiform or cartwheel pattern. Because mitotic activity is mild and nuclear pleomorphism is minimal, the tumor is considered to be a low degree malignancy. It infiltrates into the subcutaneous tissue as tentacles, leading to an appearance of honeycombs interspersed with the surrounding tissues, what could explain its tendency for recurrence. ${ }^{4}$

Spindle cell tumors that should be included in the histological differential diagnoses of DFSP are: cellular dermatofibroma, fibrosarcoma, malignant fibrous histiocytoma, atypical fibroxantho- ma, desmoplastic melanoma, Kaposi sarcoma, and solitary fibrous tumor. In these cases, immunohistochemistry becomes a useful resource in the differentiation because DFSP is positive for CD34 and vimentin, but not to CD44, S100 protein or XIIIa. ${ }^{5}$

Treatment consists in excision with wide safety margins, usually between $2 \mathrm{~cm}$ to $4 \mathrm{~cm}$. Currently, Mohs micrographic surgery is gaining acceptance; however, there are no double-blind long-term studies proving its superiority compared to traditional surgery. ${ }^{6}$ Radiotherapy and chemotherapy are indicated for unresectable tumors or when the patient's clinical conditions are a contraindication for the surgical procedure. Relative survival for non-metastatic disease is of $95.7 \%$ in 10 years. Despite being locally aggressive, DFSP rarely metastasizes; when it does, it is usually to lymph nodes, lungs and bones. ${ }^{7,8}$

Since the tumor is basically known by its protruding morphology, atrophic lesions might not be diagnosed early, worsening the prognosis. Even though atrophic dermatofibrosarcoma is clinically distinct, its epidemiological, histological, and therapeutic aspects are similar to the classic form. We present a case of an atrophic variant of DFSP in a 15-year-old male teenager.

\footnotetext{
Received on 27.02.2017.

Approved by the Advisory Board and accepted for publication on 19.05.2017.

* Study performed at Hospital Universitário Professor Alberto Antunes, Universidade Federal de Alagoas (HUPAA-UFAL) - Maceió (AL), Brazil. Financial support: None.

Conflict of interest: Nnone.

Service of Dermatology, Hospital Universitário Prof. Alberto Antunes. Universidade Federal de Alagoas (HUPAA-UFAL) - Maceió (AL), Brazil Service of Pathology, Hospital Universitário Prof. Alberto Antunes. Universidade Federal de Alagoas (HUPAA-UFAL) - Maceió (AL), Brazil.
}

MAILING ADDRESS:

Simone Silva da Costa Aragão

E-mail: simone.costa.medicina@hotmail.com 


\section{CASE REPORT}

A 15-year-old male patientattended the dermatology service at Hospital Universitário Professor Alberto Antunes (Hupaa) with a complaint of a painless lesion on the back that had been present for 5 years with progressive growing over the past year. On dermatological examination, there was a well-defined area of atrophy, with mild hyperpigmentation and no changes in texture (Figures 1 and 2). With the initial differentials of anetoderma, atrophoderma of Pasini and Pierini and atrophic scar, we performed an inci-

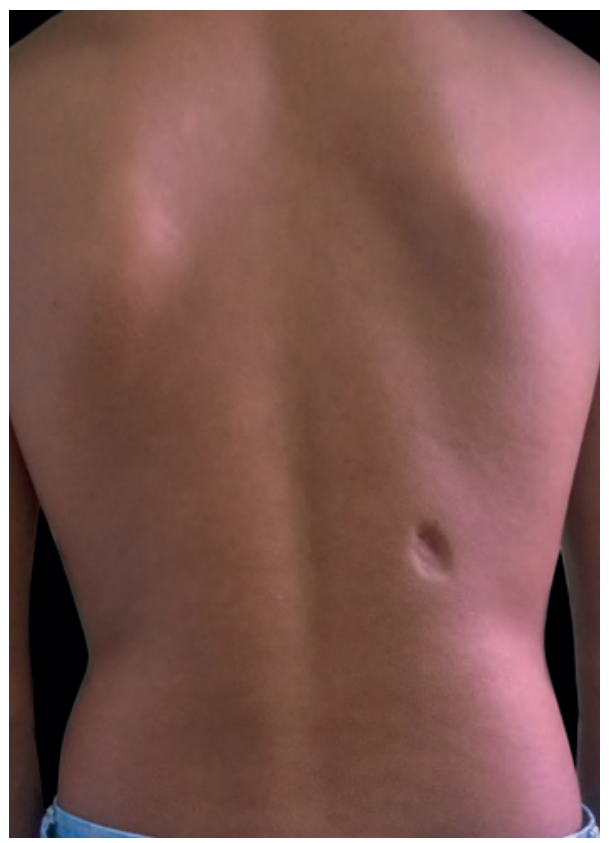

Figure 1: Atrophic lesion with mild hyperpigmentation on the back

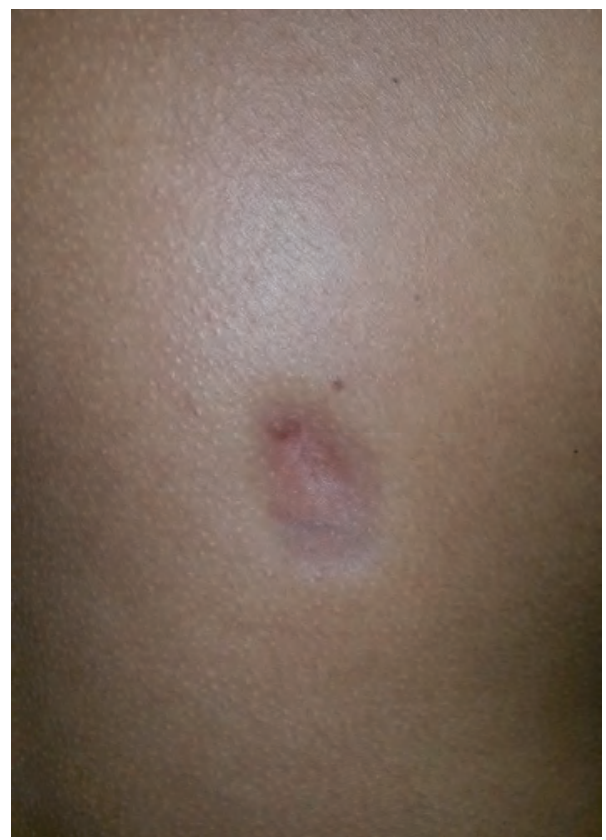

Figure 2: Close up of the atrophic lesion on the back sional biopsy that revealed a dense proliferation of monomorphic spindle cells, with elongated nuclei and interspersed in the dermis, and sparse stroma with collagen deposits, extending to the subcutaneous tissue, suggestive of neurofibroma (Figure 3). The specimen was then submitted to immunohistochemistry, that was moderately to strongly positive to CD34 and vimentin, and negative for factor XIIIa, consistent with DFSP (Figure 4). The patient underwent surgery with 2cm-margins, which where free of the tumor. He was then scheduled for follow-up every 3 months with the dermatology and oncology teams.

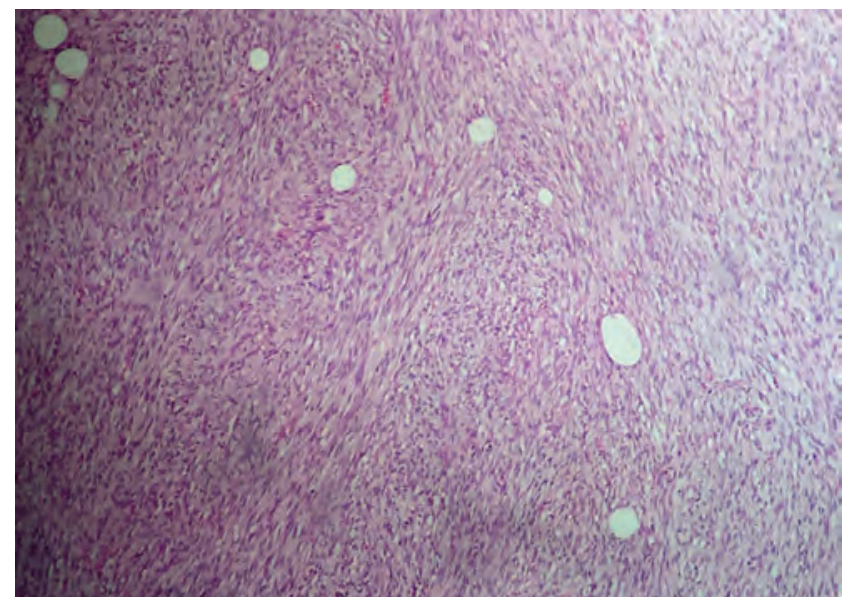

Figure 3: Histopathology of the lesion showing monomorphic spindle cells interlaced in the dermis, with elongated nuclei and extending into the subcutaneous tissue (Hematoxylin \& eosin, X4)

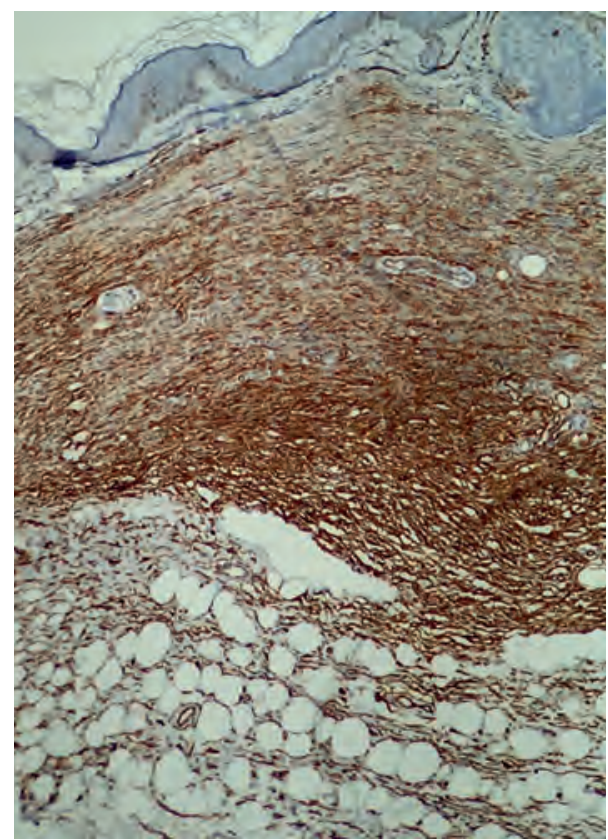

Figure 4: Immunohistochemistry of the lesion positive for CD34 (X4) 


\section{DISCUSSION}

DFSP is a clinically challenging condition. Due to its initial apparently benign and indolent behavior, many patients only seek medical care years after its onset, interfering with the prognosis.

In this case, the lesion was first noticed by the patient when he was 10 years old, presenting as an atrophic, hyperpigmented and asymptomatic lesion on the lower back. In the literature, innumerous cases are reported in the pediatric population, many of them only diagnosed in adulthood due to the lack of early diagnosis., ${ }^{2,9}$

The atrophic presentation is a rare variant, first described in 1985. Up to 2012, only 33 cases had been reported in the literature. ${ }^{10}$ It may represent an early stage prior to the development of the classical form, or remain so indefinitely. It manifests as an atrophic and asymptomatic lesion, easily mistaken for morphea, atrophic scar, sclerodermiform basal cell carcinoma, lipoatrophy, anetoderma, atrophic dermatofibroma and resolving panniculitis. ${ }^{5}$ In view of its high morbidity, we highlight the need for dermatologists to recognize rare malignancies. The atrophic variant is frequently neglected by the patients, and mistaken by benign atrophic lesions by the physicians, delaying the diagnosis and treatment and, therefore, reducing the chances for cure.

\section{REFERENCES}

1. Kumar L, Bhandari V, Singh S, Garg P, Kumar A. Giant dermatofibrosarcoma protuberans: A rare presentation over face. J Cancer Res Ther. 2015;11:1038

2. Tsai YJ, Lin PY, Chew KY, Chiang YC. Dermatofibrosarcoma protuberans in children and adolescents: clinical presentation, histology, treatment, and review of the literature. J Plast Reconstr Aesthet Surg. 2014;67:1222-9.

3. Al Barwani AS, Taif S, Al Mazrouai RA, Al Muzahmi KS, Alrawi A. Dermatofibrosarcoma Protuberans: Insights into a Rare Soft Tissue Tumor. J Clin Imaging Sci. 2016 Apr 29;6:16

4. Szollosi Z, Nemes Z. Transformed dermatofibrosarcoma protuberans: a clinicopathological study of eight cases. J Clin Pathol. 2005;58:751-6.

5. Qiao J, Patel KU, López-Terrada D, Fang H. Atrophic dermatofibrosarcoma protuberans: report of a case demonstrated by detecting COL1A1-PDGFB rearrangement. Diagn Pathol. 2012;7:166.
6. Foroozan M, Sei JF, Amini M, Beauchet A, Saiag P. Efficacy of Mohs Micrographic Surgery for the Treatment of Dermatofibrosarcoma Protuberans- Systematic Review. Arch Dermatol. 2012;148:1055-63.

7. Diniz MS, Ramos DG, Nunes MB. Dermatofibrossarcoma protuberans: localização não usual e a importância da cirurgia micrográfica de Mohs. Surg Cosmet Dermatol. 2013;5:173-6.

8. Kimmel Z, Ratner D, Kim JY, Wayne JD, Rademaker AW, Alam M. Peripheral excision margins for dermatofibrosarcoma protuberans: a meta-analysis of spatial data. Ann Surg Oncol. 2007;14:2113-20.

9. Martin L, Combemale P, Dupin M, Chouvet B, Kanitakis J, Bouyssou-Gauthier ML, et al. The atrophic variant of dermatofibrosarcoma protuberans in childhood: a report of six cases. Br J Dermatol. 1998;139:719-25.

10. Bakry 0, Attia A. Atrophic dermatofibrosarcoma protuberans. J Dermatol Case Rep. 2012;6:14-7.

How to cite this article: Aragão SSC, Leite EJS, Cardoso AEC, Houly RLS. An unusual variant of atrophic dermatofibrosarcoma protuberans. An Bras Dermatol. 2018;93(2):282-4. 